\title{
マントル対流とマグマの発生
}

\author{
名古屋大学理学部地球科学教室 島津康男 - 浦部達夫 \\ (昭和 42 年 6 月 26 日受理)
}

\section{Mantle Convection and Genesis of Magma}

\author{
Yasuo Shimazu and Tatsuo URABE \\ Department of Earth Sciences, Nagoya University
}

(Received June 26, 1967)

To explain a sharp peak of the surface heat flow distribution at the oceanic ridge, magma ascending accompanied by the mantle convection is considered. When the temperature rises beyond the melting point of basalts, magmas are assumed to be generated. A thermal effect of latent heat is taken into consideration. The magmas thus generated are moving with the convection current, or are ascending either by zone melting or by effusion. Secular variations in the distribution of the surface heat flow and in the position of magma reservoirs are shown for a two-dimensional current with $1000 \times 400 \mathrm{~km}$ scale. It is not shown that magmas can be generated at the sinking region. A similar calculation is carried out for the non-Newtonian fluid by an approximate method.

筆者らのグループは，これまで何回かにわたってマントルの対流，特にその非定常性と地質 活動との関連を論じて来た [島津・河野 $(1963,1964)$, 河野 $(1965,1966)$, 島津・入山(1966)]. その際表面熱流の分布が，oceanic ridge に見るよらな鋭いピークを示さない難点があり，こ れは Newton 流体を仮定したため全体が一様に動くからだと解釈された. Newton 流体の仮 定が数学的な便宜のためで，マントル物質の物性がそうなっていないことは確かである。しか し，温度が十分に高くてストレスが大きくない時，Newton 流体が必ずしも悪いモデルでな いことも確かである[島津 (1966)]。 また，粘性係数は温度によって変わるが，たとえばマント ル全体 (2900 km の深さ) にわたる対流の場合でも, 下部マントルの粘性係数の平均といった もので議論しても悪くない. 温度勾配の大きい表層部は（上部マントルまでも）境界層の役わ りしか果していないし，対流が進行し温度の均一化が進さにつれて，粘性係数の深さによる変 化も小さくなるからである。幅 $1000 \mathrm{~km}$ といった局地的な対流でも，いろいろの条件がミニ チュア化するだけであるから，事情は余り変らない.

そこで，表面熱流のピークをマントル物質の物性以外の原因で説明しようとすると，すず局 地的なマグマの上昇が考えられる，破壊 $\rightarrow$ 融点低下 $\rightarrow$ マグマ発生といった力学的な原因より

昭和 42 年 5 月 17 日 地震学会で発表. SMLES contribution No. 6. 
も，熱的な原因でマグマが発生するとした方 が熱力学的に妥当なことは既に述べたが [島 津 (1967)], 対流が上昇してきて融点をこえ, 液相が発生するとみる (Fig. 1)。ただしマン トル物質の一部分だけがゲンブ岩的な鉱物を もっているので, マグマは分散した液滴の形 をとるであろう。その液滴が何らかのプロセ スで集まり相当量の液塊になるとし（メカニ ズムは不問), 一旦できた液塊は，Fig. 1 に 示したよらに対流にのって流されたり(flow), zone melting で上昇して一般流からはなれ たり，極端な場合瞬間的に表面へ噴出したり (effusion) するものとする。もちろん移動す る液塊は周りに熱的な影響を与学， $U, T h$, $\mathrm{K}^{40}$ などを濃縮して熱源の移動をもひき抗こ す (Shimazu-Urabe (1967) にならって濃縮
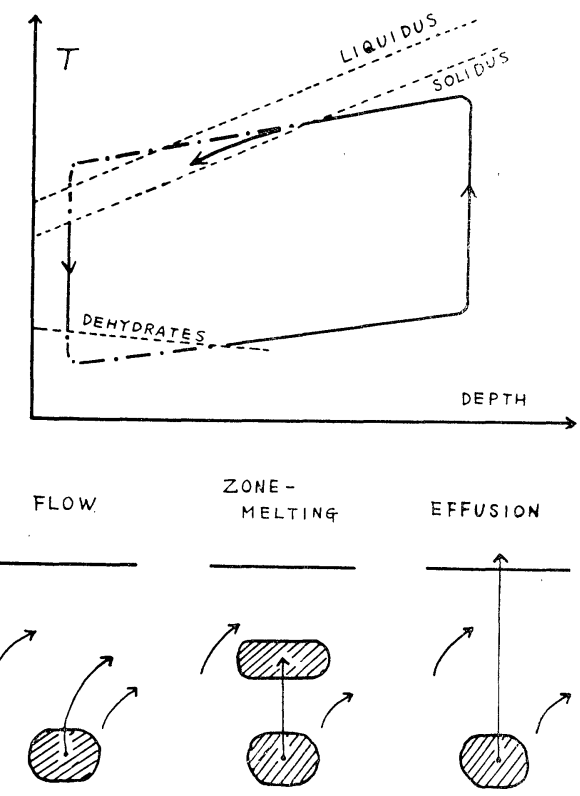

Fig. 1. Schematic illustration of $T$-depth relation for the convection current. Three types of process of magma ascending are shown.

係数は 10 とした）、マグマ上昇の型は，計算プログラムの中でパラメターを指定することに よって切りかえるものとした。ただし zone melting の上昇を正確にとくことはむずかしい ので [厳密解は Shimazu (1958) 参照], 数值積分の 1 ステップ毎に空間格子点を 1 つずつ上 昇するとした，以下に示す計算例では $5 \mathrm{~cm} /$ year 程度の上昇に当り，妥当な大きさである. 融解または固化に伴なら 潜熱の影響は，olivine-spinel 転移と 対流との関係の場合と 同じく [島津・入山 (1966)]，比熱の異常で拈きかえた。ゲンブ岩の融解開始温度は $T=1300+10 P_{k b}$ $\left({ }^{\circ} \mathrm{K}\right)$ ，融点の幅は $100^{\circ}$ ，潜熱 $=100 \mathrm{cal} / \mathrm{gr}$ （但しゲンブ岩成分はマントル物質の $20 \%$ とみ て実質は $20 \mathrm{cal} / \mathrm{gr}$ ) とする。

一方日本列島へ太平洋側からもぐりこむ対流を考える者もあるが[例吂ば Takeuchi and Uyeda (1965)], もしそらなら下降しながら融点以上に達しなくてはならない。そして地向斜 堆積物をひきずりこみながら下降し, Serpentinization による発熱反応がマグマの発生を助 ける。これらのことも考慮し, 反応の平衡温度は, 系が $\mathrm{H}_{2} \mathrm{O}$ について開いていることを考慮 して $T=$ 一定 $=800^{\circ} \mathrm{K}$, 潜熱は $50 \mathrm{cal} / \mathrm{gr}$ とする.ここで注意したいのは，融解の潜熱には 体積変化による仕事 $P \Delta V$ が加わることで，上部マントルの底の方ではエントロピー変化によ る部分（前記の $100,50 \mathrm{cal} / \mathrm{gr}$ ）と同程度またはそれ以上の大きさになる. 
島津康男・浦部達夫
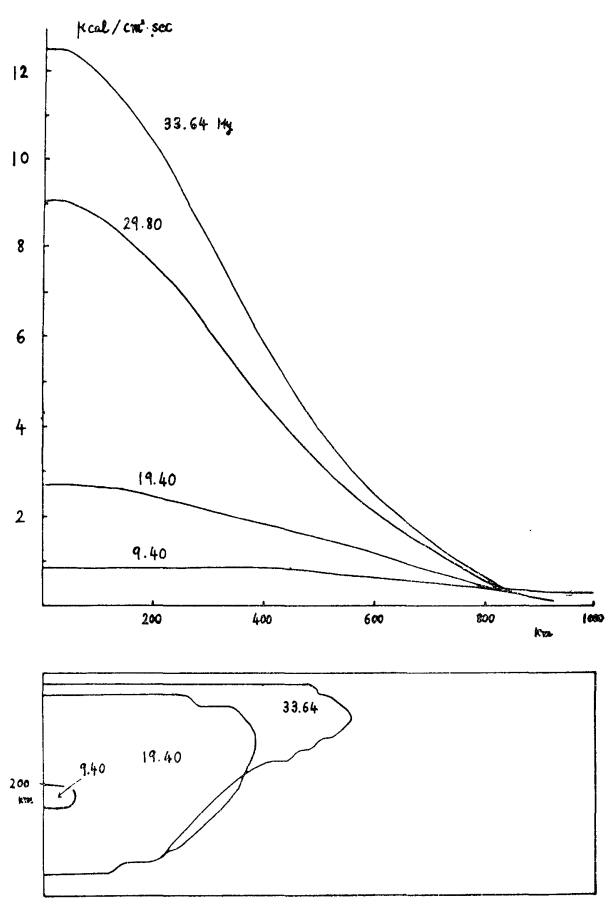

(1)
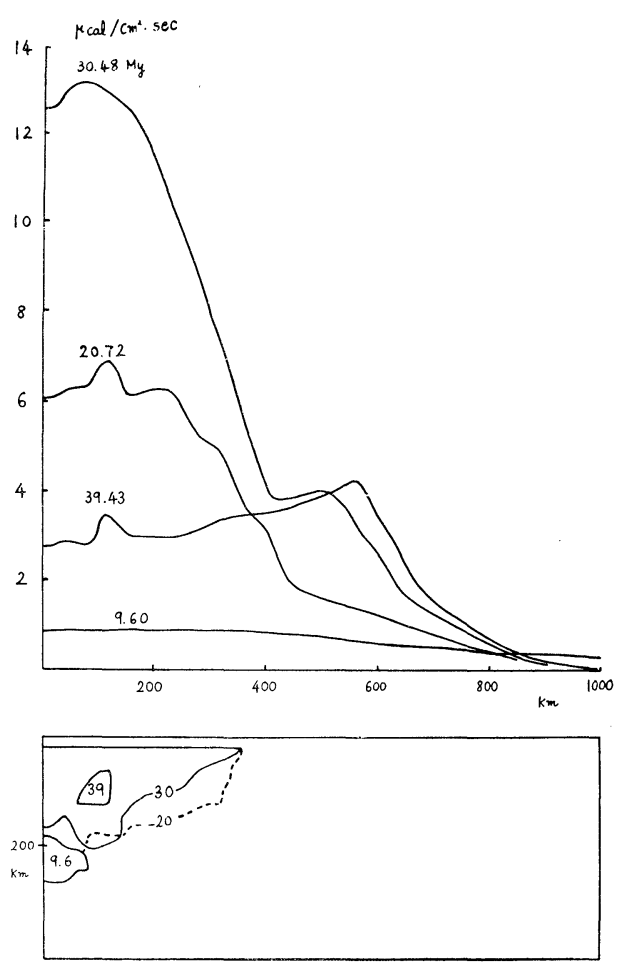

(2)

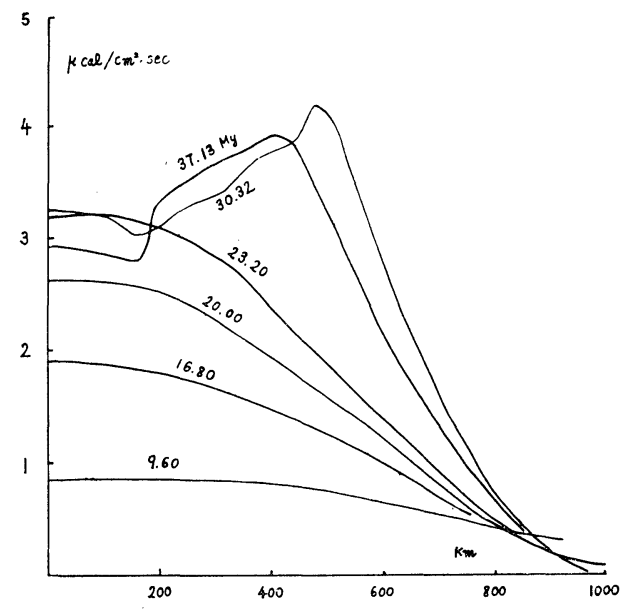

Fig. 2. Secular variations in the surface heat flow and the position of magmas. Numbers represent the time after starting in unit of $10^{6}$ years.

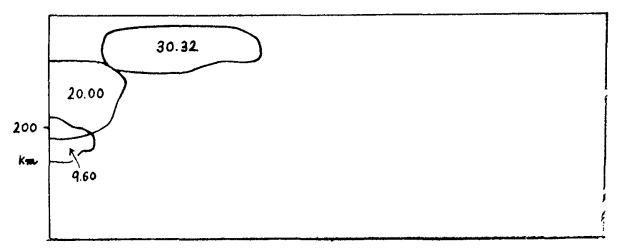

(1) flow,

(2) zone melting,

(3) effusion.

(3) 
水平スケール（上昇・下降域の距離）が $1000 \mathrm{~km}$, 厚さ $400 \mathrm{~km}$ の場合の計算例を Fig. 2 に示す. 上下面, 左右面の何れもがストレス = 自由で, 動粘性係数は $10^{22} \mathrm{~cm}^{2} / \mathrm{sec}$, 速度の 時間変化は Shimazu-Kohno (1964) の case A と同じょうな場合で，40 My の最盛期で表面 の水平速度は $1.5 \mathrm{~cm} /$ year に達する。図の上半は表面熱流の時間変化を，下半はマグマ（融 解開始温度 $+100^{\circ}$ 以上の状態）の巣の動きを表わしている。 マグマの発生深度は初期温度分 布によって変るが, 図の例は $400 \mathrm{~km}$ の深さで $2400^{\circ} \mathrm{K}$ の場合で, 大体 $200 \mathrm{~km}$ の深さで発 生しはじめ, 表面に近づきまた対流が最盛期をすぎ ると消滅することが分る。表面熱流にピークが現わ れることは注目してよい。な打下降域ではマグマは 発生しなかった。

次に Newton 流体の仮定を外し，例究ば塑性流 動の場合を考学てみよう。もちろん運動方程式をま ともにとくわ性かないから，Fig. 3 の B の上 らな速度パターンを仮定し（A は なパターン), その時間変化は Fig. 2 の場合と同じ と考えて熱輸送方程式だけをとくのである。これは Langseth ら (1966)の扱かいを非定常状態に拡張し たものにあたる。他の条件を Fig. 2 と同じにした 場合の計算例を Fig. 4 に示す。表面熱流のピーク

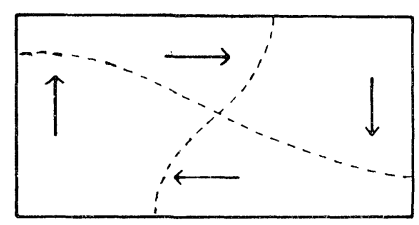
A

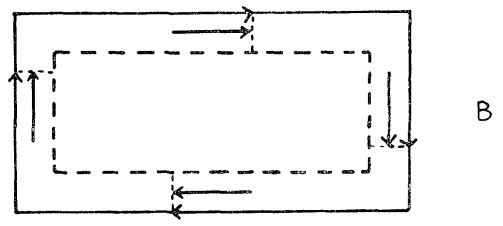

Fig. 3. Schematic illustration of velocity pattern.

(A) Newton liquid,

(B) velocity $=$ const. within the boundary layer.

は更に誇張されて現われるが，質的には Fig. 2 と余り違わない.

終りに対流の非定常性について一言して执きたい. 地質現象の原動力に対する仮説としてマ ントル対流が価值をもつのは，エネルギー収支の上で妥当ということの他に，両者が同程度の 時間スケールで進行しらることがあげられよう， ridgeや trenchには必ずはじめがあり終り がある，故にこれらの形成プロセスにマントル対流が与かるとすれば，定常対流ではありえな い. 例えば東太平洋で上昇し日本列島の近くで下降するといった $10^{4} \mathrm{~km}$ ものスケールの対流 を想定するなら, ridge, trench の対は $10^{8}$ years 程度の時代差をもって生成されたことにな る $\left(10^{4} \mathrm{~km}\right.$ を数 $\mathrm{cm} / \mathrm{y}$ で動くとして)，そのように大きな対流は $10^{8}$ years のスケールでみ た時定常ではないからである。対流パターンの物理的な安定性だけの問題ではない，対流のス ケールが $10^{3} \mathrm{~km}$ のオーダーなら, ridge, trench の同時性（地質学的時間スケールで）は保 証されよう. 小さな対流の妥当性に関する別の理由は他のところで論じた [島津 (1967)]. 

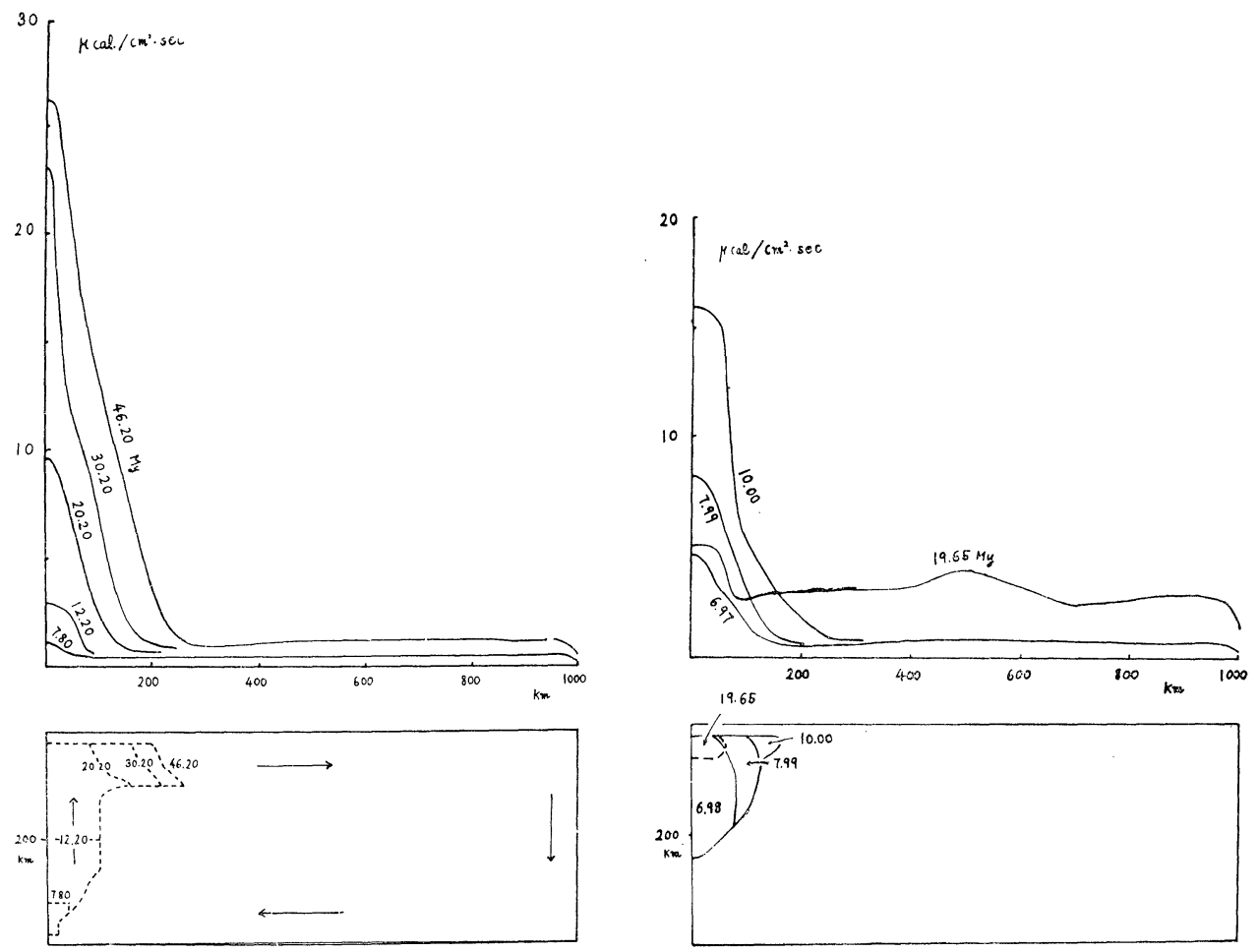

(1)

(2)

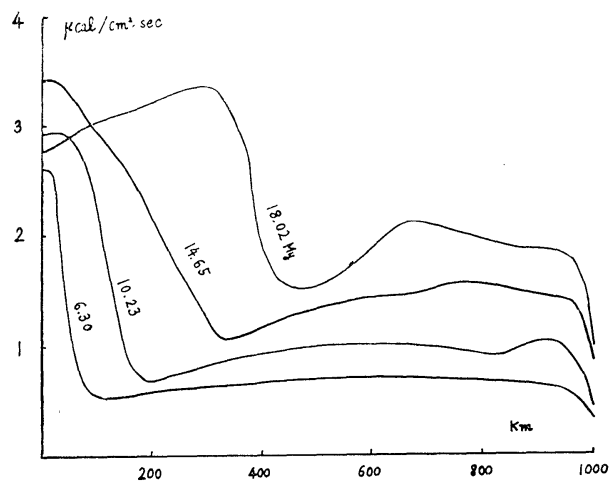

Fig. 4. Secular variations in the surface heat flow and the position of magmas. Velocity pattern is assumed as shown in Fig. (B).
(1) flow,
(2) zone melting,
(3) effusion. 
本研究の計算は東京大学大型計算機センターの HITAC $5020 \mathrm{E}$ につて行なつた（課題番 号 $4001 \mathrm{~B} 00080$ ).

\section{文献}

河野芳輝，1965，マントルからの熱流量と造構作用．地震，18，154 168.

河野芳輝，1966，マントル対流渦内の応力分布と対流によるマントルの攪拌. ibid., 19, 176 186.

Langseth, M. G., X. Le Pichon and M. Ewing, 1966, Crustal structure of the mid-oceanic ridges. 5. Heat flow through the Atlantic ocean floor and convection currents. Jour. Geophys. Res. 71, 5321 5355.

Shimazu, Y., 1958, Physical theory of generation, upward transfer, differentiation, solidification, and explosion of magmas. Jour. Earth Sci. Nagoya Univ., 8, 72 85.

島津康男, 1966, 地球内部物理学. 裳華房, pp. 394.

島津康男, 1967, 地球の進化. 岩波, pp. 359.

島津康男，河野芳輝，1963，1964，上部マントルの非定常熱対流と造構作用．地震，16，115 122; $17,148 \sim 157$.

島津康男, 入山 淳, 1966，マントルの非定常熱対流．地震， 19，272 277.

Shimazu, Y., T. Urabe, 1967, Development of the earth's mantle and beheviour of minor elements. Geochem. Jour. 1, 71 94.

Takeuchi, H., S. Uyeda, 1965, A possibility of present-day regional metamorphism. Tectonophys. 2, $59 \sim 68$. 